\title{
As atuações do enfermeiro relacionadas ao teste rápido anti-HIV diagnóstico: uma reflexão de interesse da enfermagem e da saúde pública
}

Recebido em: 07/12/2010

Aceito em: 21/03/2011
Onã Silva ${ }^{1}$

Leonor H. Lannoy Tavares ${ }^{2}$ Leidjany Costa $\mathrm{Paz}^{3}$

Frequentemente, o Ministério da Saúde publica diretrizes para o enfrentamento da epidemia da Aids. Para reduzir a transmissão vertical e ampliar o diagnóstico do HIV, algumas regiões do Brasil implantaram o Teste Rápido Anti-HIV Diagnóstico, com atuações importantes do enfermeiro relacionadas a essa metodologia. Observa-se a necessidade de estudos analisando o exercício do profissional de enfermagem na solicitação, realização, interpretação e comunicação do resultado dessa testagem às parturientes e/ou puérperas. Este ensaio reflete sobre a temática, sendo útil aos profissionais de enfermagem envolvidos no atendimento às gestantes e seus bebês, aprimorando a qualidade do pré-natal e a redução da transmissão vertical do HIV.

Descritores: Exercício da Enfermagem, Gestantes, Parturientes, Transmissão Vertical, Teste Rápido Anti-HIV Diagnóstico.

\section{The activities of the nurse related to the anti-HIV Quick Diagnostic Test: a reflection that interests nursing and public health}

Frequently, the Ministry of Health publishes guidelines to the tackling of the Aids epidemic. In order to reduce the vertical transmission and the diagnostic expansion of the HIV, some regions of Brazil have implemented the Anti-HIV Quick Diagnostic Test, and nurses have an important role in this methodology. The necessity of studies that analyze the exercise of the nursing professional during the requesting, realization and notification of these tests to the pregnant or pos-pregnant woman can be noted. This essay meditates about the thematic, being useful to the nursing staff involved in the caring of pregnant women and their babies, improving the quality of prenatal care and the reduction of HIV's vertical transmission.

Descriptors: Nursing Practice, Pregnant Woman, Pos-Pregnant Woman, Vertical Transmission, Anti-HIV Quick Diagnostic Test.

Prácticas de enfermería relacionadas a pruebas rápidas para diagnóstico de HIV: una reflexión de interés para la enfermería y la salud pública A menudo, el Ministerio de Salud publica directrices para hacer frente a la epidemia del SIDA. Para reducir la transmisión vertical del HIV y la expansión del diagnóstico, algunas regiones del Brasil implantaron la prueba rápida de diagnóstico de HIV donde las enfermeras desarrollan un papel muy importante en la metodología. Se constata la necesidad de estúdios que analicen el desempeño del personal de enfermería en la solicitud, realización y comunicación de los resultados de estos exámenes a mujeres embarazadas y / o mujeres después del parto. Este ensayo es una reflexión sobre el tema que debe servir a los profesionales de enfermería involucrados en dar asistencia a las mujeres embarazadas y sus bebés, a fin de mejorar la calidad del cuidado prenatal y reducir la transmisión vertical del HIV.

Descriptores: Práctica de la Enfermería, Mujer Embarazada, Parturienta, Transmisión Vertical, Diagnóstico Rápido de HIV.

\section{INTRODUÇÃO}

A s pesquisas sobre transmissão vertical do HIV, e em particular que analisam o exercício do profissional de enfermagem nas ações de aconselhamento - pré e pós-testagem -, bem como na solicitação, realização, interpretação e comunicação do resultado às parturientes ou puérperas submetidas a teste rápido anti-HIV, são objeto de estudo não explorado.

A transmissão vertical do HIV (TV HIV) é uma fonte de infecção importante para os casos de Aids - portanto, um desafio às políticas de saúde do Brasil. As diretrizes pró-redução da transmissão vertical do HIV são formuladas e implementadas pelo Departamento Nacional de DST e Aids (DN-DST/Aids) do Ministério da Saúde. Nessa direção, existem metas desse Departamento visando à proteção das mulheres, à ampliação do diagnóstico precoce, à realização de pesquisas para a prevenção dos agravos e ao fortalecimento de parcerias entre os Ministérios, estados, municípios, organizações não-governamentais, sociedades científicas, universidades e demais instituições envolvidas com o tema ${ }^{(1)}$.

1 Enfermeira. Mestre em educação. Docente da Escola Superior de Ciências da Saúde (ESCS/SES-DF). Atua na área de vigilância epidemiológica - Gerência de DST e Aids/Divep/ SVS/SES-DF. Email: onatil@gmail.com.

2 Enfermeira. Mestre em ciências da saúde. Docente da Escola Superior de Ciências da Saúde (ESCS/SES-DF). Atua na área de vigilância epidemiológica - Gerência de DST e Aids/Divep/SES-DF.

3 Enfermeira. Mestre em avaliação de programas e processos em saúde. Atua na área de vigilância epidemiológica - Gerência de DST e Aids/Divep/SES. 
Uma diretriz importante foi o Projeto Nascer-Maternidades, instituído no âmbito do Sistema Único de Saúde (SUS), com fulcro nos seguintes considerandos referentes à transmissão vertical do HIV (TV HIV): é a fonte de infecção nos casos de Aids em menores de 13 anos de idade; a incidência de TV HIV é de 25,5\% na ausência de procedimentos profiláticos; o uso do Protocolo 076 reduz a TV HIV em 67,5\% ao adotar a quimioprofilaxia com AZT e a nãoamamentação; $65 \%$ dos casos de TV HIV ocorrem no trabalho de parto; a amamentação representa risco adicional de $7 \%$ a $22 \%$; a testagem anti-HIV no pré-natal é menor que $40 \%{ }^{(2-4)}$.

Desde 2002, as ações prioritárias oferecem suporte às maternidades ao atendimento à gestante HIV+ ou com sífilis e respectivos recém-nascidos, bem como a ampliação do diagnóstico e atenção à mulher durante o ciclo gravídicopuerperal $^{(2,5)}$.

O acesso ao diagnóstico do HIV é direito de toda gestante/ parturiente. Recomenda-se oferecer o teste anti-HIV - com aconselhamento e consentimento - na primeira consulta de prénatal e a repetição da testagem, no início do terceiro trimestre.

Frente ao exposto, a relevância do ensaio deve-se à escassez de dados no Brasil sobre o papel do enfermeiro relacionado à testagem rápida anti-HIV. Por isso, este ensaio objetiva refletir sobre as distintas ações a serem desenvolvidas pelo enfermeiro no aconselhamento pré e pós-testagem e solicitação, realização, interpretação e comunicação do resultado do teste rápido anti-HIV para fins de diagnóstico.

\section{REVISÃO DA LITERATURA}

\section{Transmissão vertical do HIV - princípios} gerais do HIV

Dados epidemiológicos revelam que $65 \%$ dos casos de transmissão vertical do HIV ocorrem no parto e $35 \%$ ocorrem intraútero, principalmente nas últimas semanas de gestação. Existe também o risco adicional de transmissão pelo aleitamento materno, entre $7 \%$ a $22 \%$, renovando o risco a cada exposição da criança ao peito. Esse risco se eleva aproximadamente em $30 \%$ quando a infecção da mãe ocorre durante o período de amamentação(5).

Consoante à patogênese, a transmissão vertical do HIV está relacionada à carga viral, genótipo e fenótipo viral; fatores maternos (estado clínico, nutricional e imunológico, presença de DST e outras infecções, uso de antirretrovirais na gestação); fatores comportamentais (uso de drogas e prática sexual desprotegida); fatores obstétricos (tempo de ruptura das membranas amnióticas, via de parto e hemorragia intraparto); fatores inerentes ao recémnato (prematuridade e baixo peso ao nascer); e fatores relacionados ao aleitamento materno.

Ressalta-se que diversos estudos comprovam a redução da transmissão vertical do HIV para níveis entre zero e $2 \%$ com o uso de antirretrovirais combinados, a cesariana eletiva e quando a carga viral é menor do que 1.000 cópias $/ \mathrm{ml}$ ao fim da gestação(4)

Destarte, as evidências epidemiológicas subsidiam as ações pró-redução da transmissão vertical do HIV, entre elas a testagem rápida anti-HIV. De igual modo, a realização desse procedimento requer capacitação dos profissionais de saúde, especialmente do enfermeiro.

\section{Teste rápido anti-HIV}

Referente aos testes rápidos anti-HIV, diversas justificativas corroboram o uso dos mesmos: a metodologia de testagem é simples e produz resultado em, no máximo, 30 minutos; são acondicionados separadamente, permitindo a testagem individual; apresentam sensibilidade e especificidade similares aos Elisa (EIA) e Westem Blot (WB); a coleta da amostra de sangue é pela punção da polpa digital do indivíduo.

Quanto à indicação, os testes rápidos são utilizados em situações de profilaxia emergencial: a prevenção da TV HIV em parturientes ou puérperas sem testes anti-HIV no pré-natal ou resultado não disponível; situações de acidente ocupacional, sendo a testagem realizada no paciente-fonte; violência de gênero/violência sexual, sendo a testagem no violentador e para fins de diagnóstico.

Em 2005, instituiu-se a Portaria no 34/05, visando a regulamentar o uso dos testes rápidos antiHIV diagnóstico em situações especiais. Essa legislação objetiva a ampliação do acesso ao diagnóstico da infecção pelo HIV, tendo como justificativa o fato de que o conhecimento do status sorológico e o diagnóstico precoce contribuem para interromper a cadeia de transmissão. Ademais, consta a implantação do uso de testes rápidos anti-HIV diagnóstico em serviços de saúde com organização precária ou localizados em áreas de difícil acesso: Art. $2^{\circ}$ - "O diagnóstico da infecção pelo HIV poderá ser realizado em serviços de saúde localizados em áreas de difícil acesso, em maternidades e em parturientes que não tenham sido testadas para o anti-HIV no pré-natal"(6).

Em 2006, o DN-DST e Aids preconizou o teste às parturientes ou puérperas sem o resultado do anti-HIV no terceiro trimestre de gestação - ou com diagnóstico negativo anterior - para reavaliar o diagnóstico de infecção pelo HIV devido à possibilidade de janelaimunológica, pelas vantagens do resultado imediato e a redução das perdas pelo não-retorno.

Quanto ao profissional habilitado para realizar o teste rápido anti-HIV e informar o resultado - seja ele reagente ou não reagente -, seguem as prerrogativas:"Os testes rápidos para o diagnóstico da infecção pelo HIV serão realizados exclusivamente por profissionais de saúde capacitados, segundo programa de treinamento a ser definido pela SVA/MS" ${ }^{\prime \prime}(6,7)$. Portanto, tais normatizações preveem a participação e o envolvimento de enfermeiros diretamente nas ações relacionadas à testagem rápida.

\section{Testagem rápida e aconselhamento pré e pós-teste anti-HIV}

O uso dos testes rápidos permite conhecer o status sorológico da mulher no momento do parto - a última chance de intervenção profilática emergencial ao recém-nato exposto ao HIV. O teste anti- 
HIV deve ser voluntário e confidencial e o acesso ao diagnóstico é direito da gestante.

O diagnóstico da infecção pelo HIV, no início da gestação, possibilita os melhores resultados no controle da infecção materna e resultados profiláticos da transmissão vertical. As mulheres que, apesar de testadas no trabalho de parto, não apresentarem o resultado sorológico precisam ser aconselhadas a utilizar testes rápidos anti-HIV.

\section{Aconselhamento}

Uma das ações mais importantes a serem desenvolvidas pelo enfermeiro no protocolo de testagem é o aconselhamento em seus momentos distintos: pré e pós-testagem.

O profissional de enfermagem capacitado e sensível torna o aconselhamento um processo de escuta ativo, gerando relação de confiança com a mãe, minimizando dilemas e estressores decorrentes do resultado. A qualidade desse processo permite ao profissional avaliar situações de exposição ao risco de infecção pelo HIV e outras DST (para a mulher ou seu parceiro); e, para a mulher, é uma oportunidade de se preparar para receber o diagnóstico de HIV ou para a adoção das medidas de prevenção dessa infecção e de outras DST ${ }^{(4)}$.

\section{Aconselhamento pré-teste anti-HIV}

Para entender os dilemas das mulheres quanto à infecção pelo HIV, é mister aos profissionais de enfermagem que atuam na atenção ao pré-natal e na assistência ao parto frequentemente aperfeiçoar a escuta e a abordagem profissional, respeitando questões biológicas e psicossociais. Por exemplo, palestras e outras abordagens facilitam o processo de aconselhamento às gestantes e seus parceiros, na rotina dos serviços de pré-natal.

Esse espaço tem assim por finalidade facilitar a etapa posterior à gestante e ao profissional de saúde que fará o aconselhamento pré e pós-teste anti-HIV. O aconselhamento não se esgota na simples oferta e consentimento para a realização do teste anti-HIV.

\section{Aconselhamento pós-teste anti-HIV}

Nessa etapa, o profissional de enfermagem deve esclarecer a gestante/parturiente/puérpera sobre o significado do resultado da testagem e, qualquer que seja ele, informar a respeito do modo de transmissão do HIV e outras DST, além de medidas de prevenção primária ou de prevenção de reinfecção.

Durante essa fase, o profissional deve avaliar as condições emocionais e psicológicas, utilizando linguagem simples e clara, abordando-a sem julgamentos, evitando atitudes coercitivas (não impondo decisões) e informando sobre a confidencialidade/sigilo das informações compartilhadas.

Diante de resultado negativo, o aconselhamento é de suma importância. Esse resultado pode significar que a mulher não está infectada ou foi infectada recentemente e o organismo ainda não produziu anticorpos que poderiam ser detectados pelo teste. Assim, nova testagem pode ser necessária; ou seja, as informações indicarão, ou não, se a mulher pode se encontrar em "janela imunológica”; e o teste deverá ser repetido após 30 dias. Nesta situação, além dos esclarecimentos, o enfermeiro precisa oferecer suporte psicológico até a realização da nova testagem. Deve ressaltar que o teste negativo não significa prevenção nem imunidade e informar que a cada nova gestação o teste anti-HIV deverá ser repetido.

Também realiza-se o aconselhamento diante de resultado indeterminado. Tal resultado pode significar um falso-positivo ou verdadeiro-positivo de uma infecção recente, cujos anticorpos anti-HIV circulantes estão indetectáveis pelo teste ${ }^{(4)}$. Nesses casos, o teste deverá ser repetido após 30 dias, sendo importante avaliar a história, o risco de exposição e a triagem sorológica do parceiro.

Em se tratando de aconselhamento diante do resultado positivo, após os momentos iniciais da revelação diagnóstica, o enfermeiro deve estar atento a todas as reações da mulher geradas pelo impacto da diagnose. Esclarecer que estar infectada pelo HIV não significa portar a Aids, que existem remédios para controlar a infecção e reduzir a transmissão do vírus ao bebê. Encaminhar, em caráter prioritário, ao serviço de pré-natal de referência para gestantes HIV positivas.

A mulher deverá ser informada sobre a importância da terapia antirretroviral durante a gestação, do uso do AZT injetável durante o parto e do AZT oral pelo recémnascido nas primeiras seis semanas (42 dias) de vida. Ademais, o enfermeiro deve assegurar o tempo necessário para a mulher - e somente ela - sinalizar o momento e a pessoa que deve compartilhar com ela o diagnóstico positivo.

Nesse momento de revelação diagnóstica, a abordagem do enfermeiro deve ser feita de forma especial, de modo que a gestante/parturiente possa vivenciar os dilemas e encontrar as formas de enfrentamento do diagnóstico.

São muitos os estressores que a mulher enfrentará, e o enfermeiro precisa manejar tais situações com bastante habilidade. Os estressores referem-se à diversidade de informações sobre o controle e a prevenção da transmissão vertical do HIV; à necessidade de o filho ser acompanhado em serviço especializado para crianças expostas ao HIV; à necessidade da testagem anti-HIV no parceiro; uso do preservativo nas relações sexuais para prevenir a transmissão; a "desconstrução da vontade de amamentar", quando a mulher precisa ser informada de como estabelecer e fortalecer o vínculo com o filho; o preparo e administração da fórmula infantil e a introdução gradativa de outros alimentos; e de manter em sigilo o status sorológico de portadora do HIV.

\section{REFLEXÃO BASEADA NA EXPERIÊNCIA DO DISTRITO FEDERAL}

A revisão da literatura destaca a importância do enfermeiro nas diversas ações relacionadas à atenção à gestante, parturiente e puérpera e, especificamente, quanto as fases do teste rápido: aconselhamento pré e pós-testagem e ao procedimento que 
envolve a solicitação, realização, interpretação e comunicação do resultado do teste rápido anti-HIV diagnóstico.

Destarte, urge refletir sobre o papel do enfermeiro frente a esse problema de saúde pública que é a transmissão materno-fetal do HIV e nas situações em que está prevista a realização da testagem rápida e as diversas atribuições inerentes ao procedimento diagnóstico.

Visando a contribuir com essa reflexão, vale ressaltar uma experiência bem-sucedida na temática, ocorrida no âmbito da Secretaria de Estado de Saúde do Distrito Federal, planejada pela Gerência de DST e Aids (GDST) $)^{(8)}$.

Considerando as diretrizes exaradas pelo Ministério da Saúde - Plano Operacional para Redução da Transmissão Vertical do HIV e da Sífilis, a implantação do teste rápido no Brasil em 2007, a GDST-DF realizou o seminário "Pactuando Ações Pró-Redução da Transmissão Vertical do HIV e Síflis", visando ao estudo, à discussão e à pactuação de ações na temática, inclusive relacionadas à atuação do enfermeiro diante das situações que exigem a realização do teste rápido. Em todas as etapas, houve participação de equipe multiprofissional, permitindo discussão ampliada da temática.

Cerca de 200 profissionais de saúde de diferentes categorias e níveis de atenção participaram do processo de trabalho. A equipe partícipe atua em várias unidades da SES-DF, DN-DST-Aids/MS e Conselhos de Órgãos de Classe de Enfermagem, Farmácia e Medicina. A SES-DF foi representada pelas Subsecretarias de Vigilância à Saúde e Atenção à Saúde, Diretoria de Vigilância Epidemiológica, Laboratório Central, Coordenadores de Patologia Clínica e Saúde da Mulher e da Criança, Programa de Saúde da Família, Diretores Regionais de Saúde, gerentes e chefes (enfermagem, laboratório, farmácia, vigilância epidemiológica), Centro de Testagem e Aconselhamento (CTA), Centros de Referência em DST e Aids, multiplicadores da metodologia de teste rápido anti-HIV diagnóstico e do CBVE da TV do HIV e Sífilis.

Destaca-se o fato de que a temática do seminário e o teor das 25 ações pactuadas foram amplamente estudados: a equipe recebeu suporte teórico para subsidiar o debate com, principalmente, normas, portarias e manuais publicados pelo DN-DST-Aids/MS ${ }^{(9-}$ 16). Adotou-se a metodologia didática participativa.

A matéria consensuada resultou na publicação da Portaria no 37/2008, no Diário Oficial do DF (DODF), regulamentando a norma pactuada e respectivos formulários ${ }^{(17)}$. Outro documento ímpar foi o Parecer Técnico Coren-DF no 005/2007, respaldando o profissional de enfermagem a realizar o teste rápido anti$\mathrm{HIV}^{(18)}$. Ambas as publicações são relevantes pelo amparo legal às condutas profissionais, por atribuir e definir papéis nas ações relacionadas à redução da TV do HIV e da síflis.

Ressalta-se, ainda, a pactuação firmada com enfermeiros e médicos para que realizassem a testagem rápida anti-HIV.Tal acordo ocorreu mediante diálogo e argumentos teóricos substanciais quanto à importância da testagem na redução da TV do HIV e o fato de que não há implicação ético-legal ao profissional de saúde devidamente capacitado de executar esse procedimento ${ }^{(16-19)}$.

A partir de dezembro de 2007, começou a capacitação de enfermeiros do Centro Obstétrico do Hospital Regional do Gama na metodologia de TR anti-HIV triagem. Também em dezembro, teve início o processo de implantação do teste rápido anti-HIV diagnóstico na Regional de Samambaia (RSam). A partir de março de 2008, iniciaram-se as capacitações dos profissionais de saúde que atuam nas Unidades Básicas de Saúde, Centros Obstétricos e Maternidades na SES-DF. Até o presente momento, foram capacitados 203 profissionais da SES-DF, sendo $127(62,6 \%)$ enfermeiros, $51(25,1 \%)$ médicos, 12 (5,9\%) biomédicos, nove $(4,4 \%)$ farmacêuticos, dois $(1,0 \%)$ assistentes sociais, um $(0,5 \%)$ terapeuta ocupacional e um $(0,5 \%)$ psicólogo.

Interessante observar que, entre os profissionais capacitados na metodologia de testagem rápida, a maioria constituiu-se de enfermeiros. Tal resultado encontrado na experiência do DF remete às discussões preparatórias ocorridas na implantação da tecnologia diagnóstica. Sem dúvida, aquele momento de pactuação foi relevante para a enfermagem, que construiu conhecimento sobre as ações múltiplas que pode desenvolver para reduzir a transmissão materno-fetal do HIV.

\section{CONSIDERAÇÕES FINAIS}

A participaçãodoenfermeirovisando a alcançar a meta do Ministério da Saúde de reduzir a TV do HIV no Brasil é fundamental. Sem dúvida, esse profissional desenvolve atividades relevantes para a saúde pública desde as instâncias da política de redução dos agravos até as instâncias de atendimento integral às gestantes, parturientes e puérperas.

É importante destacar que o teste rápido e novas tecnologias estão chegando ao setor de saúde e imprimem mudanças nas atribuições das diversas categorias profissionais. Nesse contexto, a enfermagem precisa atualizar os conhecimentos - dever profissional contido na Lei do Exercício Profissional(16) ${ }^{(16}$ e incorporar tais avanços em sua prática.

Entre as múltiplas atuações do enfermeiro, podem ser destacadas aquelas relacionadas à prevenção do agravo entre elas o incentivo da gestante/parturiente/parceiro aos exames anti-HIV para o conhecimento do status sorológico - e atuações promotoras à saúde, visando à qualidade de vida dos portadores do HIV.

Destacamos ainda a atuação marcante do enfermeiro na atenção ao pré-natal, integrada à equipe de saúde, fazendo cumprir o protocolo de testagem ainda nessa fase, minimizando a indicação do teste rápido no parto - momento em que a equipe de enfermagem se encontra sobrecarregada com outras atribuições. Mas, de igual modo, o enfermeiro precisa compreender as práticas relacionadas à redução da TV HIV de forma integral, incluindo a importante ação que é a última chance diagnóstica - o teste rápido anti-HIV diagnóstico -, indicado à parturiente ou puérpera não testada no terceiro trimestre, sem o cartão ou sem o resultado no cartão. 
As atuações positivas da enfermagem relacionadas ao teste rápido têm impacto epidemiológico, e experiências como as do Distrito Federal e de outros estadosque conferem o protagonismo da profissão são marco histórico para a saúde pública brasileira.

Exemplifica-se que as ações do enfermeiro relacionadas ao teste rápido estão sendo normatizadas, com base em argumentos teóricos e legislações específicas que respaldam a atuação - principalmente a Lei do Exercício Profissional de Enfermagem, que consta sobre a atuação do enfermeiro na realização de exames ${ }^{(16)}$-, conferindo amparo legal para realizar o procedimento sem implicações ético-legais.

Importantes publicações de normativas que contribuem para essa reflexão referem-se à Portaria $n^{\circ} 37 / 2008$, que é uma norma estadual da Secretaria de Estado de Saúde (SES-DF), publicada em Diário Oficial, assim como o Parecer Técnico Coren-DF n 005/2007 e, recentemente, o Parecer Técnico Coren-DF no 019/2010 ${ }^{(19)}$, que concluem pelo parecer favorável aos profissionais de enfermagem para realizar o TR anti-HIV diagnóstico.

Nós, autoras, estamos em constante reflexão e ação nessa temática: avaliando e reavaliando nossos papéis como enfermeiras nas áreas de assistência, vigilância, ensino; realizando capacitações aos profissionais e orientações às Unidades Básicas de Saúde, principalmente na atenção à gestante; e, ainda, monitorando as ações pactuadas e estabelecidas na Portaria n 37/2008.

Nosso objetivo nesta reflexão é que um número maior de enfermeiros também reflita e desenvolva ações relevantes sobre esta questão de saúde pública: a transmissão vertical do HIV. Enfim, refletindo e atuando continuamente, a categoria de enfermagem pode fazer diferença significativa na saúde pública brasileira, reduzindo o agravo mediante desenvolvimento de diversas ações pró-redução da transmissão vertical do HIV.

\section{Referências}

1. Ministério da Saúde (BR). Plano Operacional para Redução da Transmissão Vertical do HIV e da Sífilis. Brasilia: Ministério da Saúde; 2007.

2. Ministério da Saúde (BR). Coordenação Nacional de DST e Aids. Projeto Nascer. Brasilia: Ministério da Saúde; 2003.

3. Ministério da Saúde (BR). Portaria no 1071/GM de 9 de julho de 2003. Dispöe sobre o leite artificial [lnternet]. [citado em 30 Jan 2011]. Disponivel em: http://dtr2001. saude.gov.br/sas/PORTARIAS/Port2003/GM/GM-1071.htm

4. Ministério da Saúde (BR). Recomendaçōes para profilaxia da transmissão vertical do HIV e terapia antirretroviral em gestantes. Brasília: Ministério da Saúde; 2006.

5. Ministério da Saúde (BR). Protocolo para a prevenção de transmissão vertical de HIV e sífilis: manual de bolso. Brasilia: Ministério da Saúde; 2007.

6. Ministério da Saúde (BR). Portaria n 34 MS/SVS, de 28 de julho de 2005.

Regulamenta o uso de testes rápidos para diagnóstico da infecção do HIV em situações especiais [Internet]. [citado em 10 Jan 2011]. Disponível em: http://bvsms. saude.gov.br/bvs/saudelegis/svs/2005/prt0034_28_07_2005.html.

7. Ministério da Saúde (BR). Portaria n 59/GM/MS, de 30 de janeiro de 2003.

Padroniza o conjunto de procedimentos sequenciados para detecção de anticorpos anti-HIV para diagnóstico laboratorial da infecção pelo HIV em indivíduos com idade acima de 2 anos [Internet]. [citado em 15 Jan 2011]. Disponível em: http://pegasus. fmrp.usp.br/projeto/legislacao/Portaria\%2059\%20de\%2028\%2001\%2003.pdf. 8. Arruda DCB, Silva O, Tavares LHDC. Experiência de pactuação pró-redução da transmissão vertical do HIV e da síflis no Distrito Federal. Bol Epidemiol Distrito Federal. 2008;7(1):6-7.

9. Ministério da Saúde (BR). Portaria nº648/GM de 28 de março de 2006.

Aprova a Política Nacional de Atenção Básica [Internet]. [citado em 30 Jan

2011]. Disponivel em: http://www.brasilsus.com.br/index.php?option=com_

content\&view=article\&id=899.

10. Ministério da Saúde (BR). Implicações éticas do diagnóstico e da triagem sorológica do HIV/Secretaria de Vigilância em Saúde, Programa Nacional de DST e Aids. Brasilia: Ministério da Saúde; 2004.

11. Ministério da Saúde (BR). Carta dos direitos dos usuários da saúde. $2^{\mathrm{a}}$ ed. Brasilia: Ministério da Saúde; 2007.

12. Ministério da Saúde (BR). Instrução Normativa n 1626 de 10 de julho de 2007.

Regulamenta os procedimentos e condutas para abordagem consentida a usuários que procuram os serviços de saúde com vistas a realizar teste de HIV e outras DST, bem como aos que não comparecem ao tratamento já em curso [Internet]. [citado em 21 Jan 2011]. Disponivel em: http://www.Aids.gov.br/sites/default/files/ Instrucao_Normativa_1626_10.07.2007.pdf.

13. Conselho Federal de Medicina. Resolução CFM 1.665 de 7 de maio de 2003. Dispõe sobre a responsabilidade ética das instituições e profissionais médicos na prevenção, controle e tratamento dos pacientes portadores do vírus da Sida (Aids) e soropositivos [Internet]. [citado em 21 Jan 2011]. Disponível em: http://www. portalmedico.org.br/resolucoes/cfm/2003/1665_2003.htm.

14. Secretaria de Estado de Saúde (DF). Portaria nº 33 de 15 de março de 2005. Institui o Projeto de Eliminação da Sífilis Congênita no Distrito Federal. [Internet]. [citado em 24 Jan 2011]. Disponível em: http://www.buriti.df.gov.br/ftp/ diariooficial/2005/03_Março/DODF\%20050\%2015-03-2005/Seção02-\%20050.pdf]. 15. Secretaria de Estado de Saúde (DF). Norma Técnica n.01 de 22 de março de 2007. Recomendações do PN-DST/Aids para uso de testes rápidos para HIV como triagem em parturientes não testadas no $3^{\circ}$ trimestre de gestação. Brasília: Secretaria de Estado de Saúde; 2007.

16. Conselho Federal de Enfermagem. Lei n 7498, de 25/07/1986: Dispõe sobre a regulamentação do exercício profissional da enfermagem [Internet]. [citado em 30 Jan 2011]. Disponível em: http://site.portalcofen.gov.br/node/4161.

17. Secretaria de Estado de Saúde (DF). Portaria n 37 de 4 de abril de 2008. Normatiza ações pró-redução da transmissão vertical do HIV e Sífilis [Internet]. [citado em 30 Jan 2011]. Disponível em: http://www.buriti.df.gov.br/ftp/ diariooficial/2008/04_Abril/DODF\%2066\%2008-04-08/Seção01-\%20066.pdf. 18. Conselho Regional de Enfermagem do DF. Parecer técnico Coren-DF nº 05 de 2007. Trata sobre competência da equipe de enfermagem para realizar a coleta, a leitura e o registro do resultado do teste rápido anti-HIV [Internet]. [citado em 25 Jan 2011]. Disponivel em: http://www.coren-df.org.br/portal/index.php?option=com_c ontent\&view=article\&id=343:parecer-tecnico-coren-df-no-0052007\&catid=38:parec eres\&ltemid=115.

19. Conselho Regional de Enfermagem do DF. Parecer técnico Coren-DF n 19 de 2010. Trata sobre a atribuição da enfermagem na realização e fornecimento do resultado teste rápido anti-HIV [Internet]. [citado em 24 Jan 2011]. Disponível em: http://www.corendf.org.br/site. 